\title{
Effect of sample orientation on the microstructure and microhardness of additively manufactured AlSi10Mg processed by high-pressure torsion
}

\author{
Shahir Mohd Yusuf ${ }^{1} \cdot$ Mathias Hoegden $^{1} \cdot$ Nong Gao $^{1}$ (D) \\ Received: 14 August 2019 / Accepted: 9 December 2019 / Published online: 15 January 2020 \\ (C) The Author(s) 2020
}

\begin{abstract}
For the first time, high-pressure torsion (HPT) was applied to additively manufactured AlSi10Mg built in two directions (vertical and horizontal) by selective laser melting (SLM), and the influence of extreme torsional strain on the porosity, microstructure and microhardness of the alloy was investigated. ImageJ analysis indicates that significant porosity reduction is achieved by $1 / 4$ HPT revolution (low strain). Optical microscopy (OM) and scanning electron microscopy (SEM) observations reveal the steady distortion and elongation of the melt pools, the continuous elongation of the cellular-dendritic Al matrix and breakage of the eutectic Si phase network with increased HPT revolutions. Microhardness measurements indicate that despite the significant increase in hardness attained from HPT processing, hardness saturation and microstructural homogeneity are not achieved even after 10 HPT revolutions. X-ray diffraction (XRD) line broadening analysis demonstrates increased dislocation densities with increased HPT revolutions, which contributes to the considerably higher hardness values compared to as-received samples.
\end{abstract}

Keywords Porosity $\cdot$ Microstructure $\cdot$ Microhardness $\cdot$ AlSi10Mg $\cdot$ Additive manufacturing $\cdot$ High-pressure torsion

\section{Introduction}

Powder bed fusion laser additive manufacturing (L-PBF AM) techniques, such as selective laser melting (SLM) and electron beam melting (EBM) have emerged as attractive methods of fabricating metallic components suitable for a wide range of applications, including automotive and aerospace. These techniques are highly attractive because they are able to manufacture engineering components with intricate structures and tailored microstructures [1]. Compared to traditional manufacturing routes, AM also offers the advantage of short lead times and low material wastage while maintaining accuracy and high resolution for the built structure [2-4]. SLM is

Nong Gao

N.Gao@soton.ac.uk

Shahir Mohd Yusuf

symy1g12@soton.ac.uk

Mathias Hoegden

mh3n16@soton.ac.uk

1 Materials Research Group, Faculty of Engineering and Physical Sciences, University of Southampton, Southampton SO17 1BJ, UK one of the most common L-PBF AM technology that builds metallic parts by selectively laser scanning a powder bed in a layer-by-layer fashion (bottom-up approach) through computer-aided design (CAD) until a complete threedimensional (3D) structure is formed.

To date, a wide range of materials have been processed by SLM, including stainless steels [5-7], Ni-based alloys [8-10], Ti-based alloys [11-13] and Al-based alloys [14-16]. Various reports have suggested improvements in mechanical properties for AM-fabricated parts compared to that of their traditional counterparts, including higher yield and tensile strengths $[17,18]$, better corrosion resistance [19-21] and enhanced fatigue life [22]. Such improvements are attributed to the unique and very fine microstructure as a result of rapid solidification due to the short laser-material interaction time and high cooling rates of AM processes $\left(10^{3}-10^{8} \mathrm{~K} \mathrm{~s}^{-1}\right)$ [23-25]. However, the high residual stress, porosity and other defects that often exist in as-manufactured parts cause some concern, which means that some kind of post-processing, e.g. hot isostatic pressing (HIP) and heat treatment before being ready for service [26-28].

On the other hand, severe plastic deformation (SPD) is a unique metal processing technique that introduces large amounts of strain on bulk metallic materials to achieve 
extreme grain refinement down to sub-micron $(0.1-1 \mu \mathrm{m})$ or even nanoscale $(<100 \mathrm{~nm})$, collectively termed ultrafine grained microstructure (UFG) [29, 30]. High-pressure torsion (HPT) is one of the most effective SPD techniques in attaining UFG microstructures with large fractions of high-angle grain boundaries via imposing significantly high torsional strains on disk-shaped materials. Various studies have shown improvement in properties of materials processed by SPD processes, in particular by HPT, compared to cast or wrought materials. Examples include higher yield and tensile strengths [31,32], enhanced wear and corrosion performance $[33,34]$ and superplasticity at room temperature $[35,36]$. The high strengths in SPD-processed metals are largely attributed to the Hall-Petch effect from the UFG microstructure and dislocation strengthening because of large amounts of dislocations introduced during SPD processing. Furthermore, reports have also emerged on attaining pore-free metallic materials via HPT, e.g. in pure $\mathrm{Cu}$ [37] and $\beta$-Ti alloys [38].

AlSi10Mg is a traditional hypoeutectic Al-Si-based cast alloy that is highly attractive for aerospace, marine and automotive applications due to its light weight, high specific strength, good corrosion resistance and low thermal expansion [39-42]. AlSi10Mg possesses good weldability due to its near Al-Si eutectic composition, in which the size and morphology of eutectic Si significantly influences the overall mechanical properties of this alloy $[43,44]$. Coarse and acicular-shaped eutectic Si phase often cause cracks in cast AlSi10Mg (cooling rate $<10^{2} \mathrm{~K} \mathrm{~s}^{-1}$ ) when placed under tensile load, resulting in mechanical performance [45]. Therefore, rapid solidification $\left(10^{3}-10^{8} \mathrm{~K} \mathrm{~s}^{-1}\right)$ is desired to attain refined $\mathrm{Si}$ phase that are distributed homogeneously in the $\mathrm{Al}$ matrix to achieve better mechanical properties [46, 47]. This can be easily achieved by AM processes, and various studies have indeed shown enhancement in strength and ductility, and other properties of AM-fabricated AlSi10Mg compared to cast or wrought counterparts [48-51].

For example, two distinct microstructures can be observed in SLM-fabricated AlSi10Mg as a result of the rapid heating/ cooling cycle: (a) cellular-dendritic $\alpha$-Al structures and (b) fine, fibrous eutectic Si phase network around the $\alpha$-Al phase $[48,49,52]$. Such unique microstructures contribute to the improved mechanical properties of SLM AlSi10Mg, e.g. strength and ductility under quasi-static loading [50, 51, 53]. Kempen et al. [48] established a process parameter window comprising of laser power, $P$ and scan speed, $v$ to achieve optimum densification levels in SLM AlSi10Mg. Wei et al. [49] found that the porosity in SLM ALSi10Mg can be controlled (but not eliminated) by adjusting the energy density parameter, particularly laser power, $P$ and laser scan spacing, h. Furthermore, Hadadzadeh et al. [54], Chen et al. [55] and Li et al. [56] all agree that the strengthening in SLM AlSi10Mg is caused by Orowan strengthening, Hall-Petch effect, dislocation hardening, or combination of the strengthening mechanisms.
On the other hand, while AlSi10Mg has not been processed by HPT yet, there are vast amount of literature on the HPT processing of other Al-Si-based alloys, e.g. Al-2Si, Al-7Si and Al-12 Si [57-60]. For example, Wang et al. [57] attributed the enhanced hardness and corrosion performance of HPTprocessed Al-7Si to breakage of coarse Si particles and intermetallic phases, microstructure homogeneity and increased active sites due to HPT. Mungole et al. [58] found a correlation between microhardness and microstructural homogeneity in HPT-processed Al-7Si. Furthermore, El Aal et al. [59] attributed the improved wear properties of HPT-processed Al$7 \mathrm{wt} . \% \mathrm{Si}$ to increased microhardness due to grain refinement to the nano-scale and the uniform dispersion of Si particles.

In fact, it is only very recently that the combination of SLM and HPT for 316L stainless steel was studied by the current authors [20]. It was found that HPT processing is able to substantially reduce porosity even at low strain levels, achieving nano-scale grain sizes and resulting in enhanced microhardness and corrosion performance. Accordingly, the objective of this study is to investigate the influence of HPT processing on the porosity, microstructure and microhardness of SLM-manufactured AlSi10Mg built on both vertical and horizontal orientations through various number of HPT revolutions (strain levels) at room temperature. Microstructural evolution of the HPT-processed alloy is characterized by optical microscopy $(\mathrm{OM})$, scanning electron microscopy (SEM), Vickers microhardness (HV) measurements and $\mathrm{x}$-ray diffraction (XRD).

\section{Materials and methods}

Gas-atomised AlSi10Mg powder supplied by Concept Laser was used in this study with the chemical composition shown in Table 1.

A Concept Laser M2 SLM machine was used to additively manufacture the AlSi10Mg samples. The processing parameters chosen were as recommended by concept laser as listed in Table 2. The samples were built in a chamber with $\mathrm{N}_{2}$ gas environment at room temperature, while an alternating bidirectional scan strategy was used in this study [61].

To investigate the influence of build orientation on the microstructure and microhardness of HPT-processed SLM AlSi10Mg, two $200 \mathrm{~mm}$ long cylindrical rods with a diameter of $10 \mathrm{~mm}$ each were manufactured in vertical and horizontal orientations, respectively, as shown in Fig. 1. In both cases,

Table 1 Chemical composition of AlSi10Mg used in this study (wt\%)

\begin{tabular}{lllllllllll}
\hline $\mathrm{Si}$ & $\mathrm{Mg}$ & $\mathrm{Cu}$ & $\mathrm{Mn}$ & $\mathrm{Fe}$ & $\mathrm{Ni}$ & $\mathrm{Zn}$ & $\mathrm{Pb}$ & $\mathrm{Sn}$ & $\mathrm{Ti}$ & $\mathrm{Al}$ \\
\hline 10.8 & 0.45 & 0.05 & 0.45 & 0.55 & 0.05 & 0.10 & 0.05 & 0.05 & 0.15 & Bal. \\
\hline
\end{tabular}


Table 2 Processing parameters used to fabricate AlSi $10 \mathrm{Mg}$ via SLM in this study

\begin{tabular}{llll}
\hline Laser power, $P(\mathrm{~W})$ & Scan speed, $v\left(\mathrm{~mm} \mathrm{~s}^{-1}\right)$ & Laser scan spacing, $h(\mu \mathrm{m})$ & Layer thickness, $d(\mu \mathrm{m})$ \\
\hline 400 & 1600 & 200 & 20 \\
\hline
\end{tabular}

the laser beam was scanned on the powder bed along the $\mathrm{x}-\mathrm{y}$ plane and moved vertically upwards along the z-axis.

For HPT processing, the cylindrical rods were sliced into thin disks with thickness of $1 \mathrm{~mm}$ and diameter of $\sim 9.8 \mathrm{~mm}$ each before being ground down with 800 grit $\mathrm{SiC}$ paper to a thickness of $\sim 0.85 \mathrm{~mm}$. Quasi-constrained HPT processing was conducted at room temperature using a HPT facility having two anvils, each containing a circular cavity with depth of $0.25 \mathrm{~mm}$ and diameter of $10 \mathrm{~mm}$, respectively [62-64]. The disks were placed inside the cavity of the lower anvil before the anvil is pushed upwards into the cavity of the upper anvil via a compressive force. A small gap existing between the anvils enables some material outflow upon HPT torsional straining. The disks were then deformed under a pressure of $6 \mathrm{GPa}$ by rotating the lower anvil at $1 \mathrm{rpm}$, from $1 / 4$ to 10 revolutions. The equivalent von Mises strain, $\varepsilon_{\text {eq. }}$. Imposed by HPT straining can be calculated by using the following equation [30]:

$\varepsilon_{e q}=\frac{2 \pi N R}{h \sqrt{3}}$

where $N$ is the number of revolutions, $R$ the distance from disk centre and $h$ the initial disk thickness.

In this paper, disk samples sliced from the vertically built rod are denoted with $N-\mathrm{V}$, while disk samples sliced from the
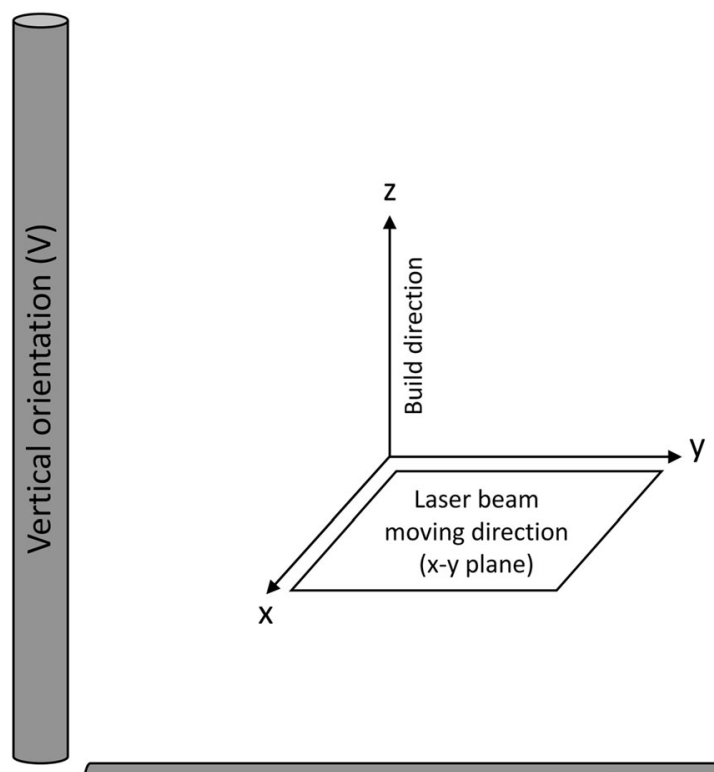

\section{Horizontal orientation $(\mathrm{H})$}

Fig. 1 Schematic of sample orientations, build direction and laser beam moving plane for the two cylindrical rods horizontally built rod are denoted as $N-\mathrm{H}$, where $N$ corresponds to the number of HPT revolutions; e.g. 1/4-V (1/4 HPT revolution, vertical), 1-H (1 HPT revolution, horizontal). On the other hand, as-received disks are denoted as AR-V (vertical) and AR-H (horizontal) respectively.

The porosity content in the as-received and HPT-processed disks was analysed using ImageJ analysis software based on images taken from OM and SEM observations following the procedures described in Ref. [20]. The microstructures of the as-received and the HPT-processed disks were characterized via OM and SEM after being ground using different grits of $\mathrm{SiC}$ paper, polished using 3 and $1 \mu \mathrm{m} \mathrm{Al}_{2} \mathrm{O}_{3}$ suspensions to a mirror-like surface finish and finally etched with Keller's reagent. OM and SEM observations were conducted on the disk surface, i.e. the circular cross-section of the rods. Thus, for vertically built samples, the disk surface is parallel to the $\mathrm{x}-\mathrm{y}$ plane, while the disk surface for horizontally built samples is parallel to the $\mathrm{x}-\mathrm{z}$ plane.

Two different sets of microhardness measurements were recorded using Future Tech FM-300 Vickers hardness testing machine under an applied load of $500 \mathrm{gf}$ with a dwell time of $15 \mathrm{~s}$. The results are expressed in two ways: as plots of hardness against distance from the centre of the disk and as 2D colour-coded contour mapping plots throughout the disk surface. Firstly, a series of HV measurements were taken across the diameter of the disks with a distance of $0.3 \mathrm{~mm}$ between one indentation point to another. To improve the accuracy of the measurements, four further HV measurements were made with distances of $0.15 \mathrm{~mm}$ around each initial indentation point. The five readings were averaged and the error bars were recorded. Secondly, microhardness measurements were taken throughout the whole surface of the disks in a rectilinear grid mapping pattern determined by $\mathrm{x}$ - and $\mathrm{y}$-coordinates, with coordinates $(0,0)$ defined as the centre of the disks. The indentation points are placed $0.3 \mathrm{~mm}$ between each other.

The phase composition and dislocation density, $\rho$, of the asreceived and HPT-processed disks were determined by x-ray diffraction (XRD) analysis using Rigaku SmartLab X-ray Diffractometer, with 10 steps per degree and a count time of $1 \mathrm{~s}$ per step on the instrument using a slit length of $5 \mathrm{~mm}$, which is equipped with a graphite monochromatore using $\mathrm{CuK} \alpha$ radiation. The phase composition was determined by the XRD peaks and peak broadening data, while the dislocation density was estimated from the microstrain, $\varepsilon$ and crystallite size, $D_{c}$ using materials analysis using diffraction (MAUD) software based on the Rietveld refinement method [65-67]. 


\section{Results and discussion}

\subsection{Porosity evolution}

Spherical and non-spherical pores were observed on the polished samples shown in Fig. 2a. The spherical pores are also known as gas-induced porosity, which could be caused by the entrapment of inert gas in the melt pool during the melting of powder or may already exist inside the initial raw powder and then remain in the finished structure $[68,69]$. The irregular-shaped pores are known as process-induced porosity, which could arise from incomplete melting of the powder as the result of insufficient energy, or due to spatter ejection from the powder bed upon contact with the laser beam [25].

The SEM image in Fig. $2 b$ shows an unmelted powder region causing lack-of-fusion porosity (a type of processinduced porosity) as the result of inadequate energy contact at that particular powder bed region to melt the powder. Etched OM image in Fig. 2c shows a mix of gas-induced pores (dashed yellow circle) and process-induced pores within the melt pool microstructure of the vertically built samples (AR-V), while etched OM image in Fig. $2 d$ indicate that process-induced pores (solid red circle) are more apparent in the horizontally built samples (AR-H). The lack of gasinduced porosity in the AR-H samples may be the result of the continuous melting and re-melting of successive layers during the SLM process, which can cause the entrapped gas to eject away from the melt pool upon contact with the laser beam [70]. On the other hand, upon scanning a single layer of powder bed for the AR-V samples, it could be more difficult for the entrapped gas to move out of the melt pool since their movement are restricted by the compact powder distribution within the layer.

Porosity measurement was conducted on polished but unetched AR-V and AR-H samples using ImageJ software to determine the initial porosity level before HPT processing. The average porosity content for AR-V samples is $0.766 \pm$ $0.023 \%$ and $0.695 \pm 0.019 \%$ for AR-H samples. Despite the slight discrepancy between porosity level in AR-V and AR-H samples, they indicate high solidification levels (>99\%) were attained for samples built in both orientations. Figures 3 a and $\mathrm{b}$ show the distribution of pore diameter in the as-received disks before HPT processing, which indicates a wide, but roughly similar distribution of pore diameter within the 0 $90 \mu \mathrm{m}$ range for both sample orientations. The slightly larger pore diameter distribution in AR-H samples may be caused by the larger process-induced pores in the horizontally built samples compared to those in the vertically built samples. The average pore diameter is $19.38 \pm 15.64 \mu \mathrm{m}$ for AR-V and $19.50 \pm 17.7 \mu \mathrm{m}$ for AR-H. Most of the pores lie between 5 and $10 \mu \mathrm{m}$ and $5-15 \mu \mathrm{m}$ for AR-V and AR-H, respectively.

After $1 / 4$ revolution of HPT processing, the porosity content is reduced to $0.045 \pm 0.011 \%$ and $0.037 \pm 0.008 \%$ for $1 / 4$ $\mathrm{V}$ and $1 / 4-\mathrm{H}$, respectively, yielding $\sim 94 \%$ decrease compared to the as-received samples. Figures $3 \mathrm{c}$ and $\mathrm{d}$ show the distribution of pore diameter for the disks processed through $1 / 4$ HPT revolution. The results indicate a much narrower distribution of pore diameter ranging from 0 to $40 \mu \mathrm{m}$ and

Fig. 2 a OM image showing types of porosity in the asreceived AlSi10Mg. b SEM image showing unmelted powder region. $\mathbf{c}$ Dashed circle showing gas-induced porosity in AR-V sample. d Process-induced porosity at the melt pool boundaries (MPB) in AR-H sample

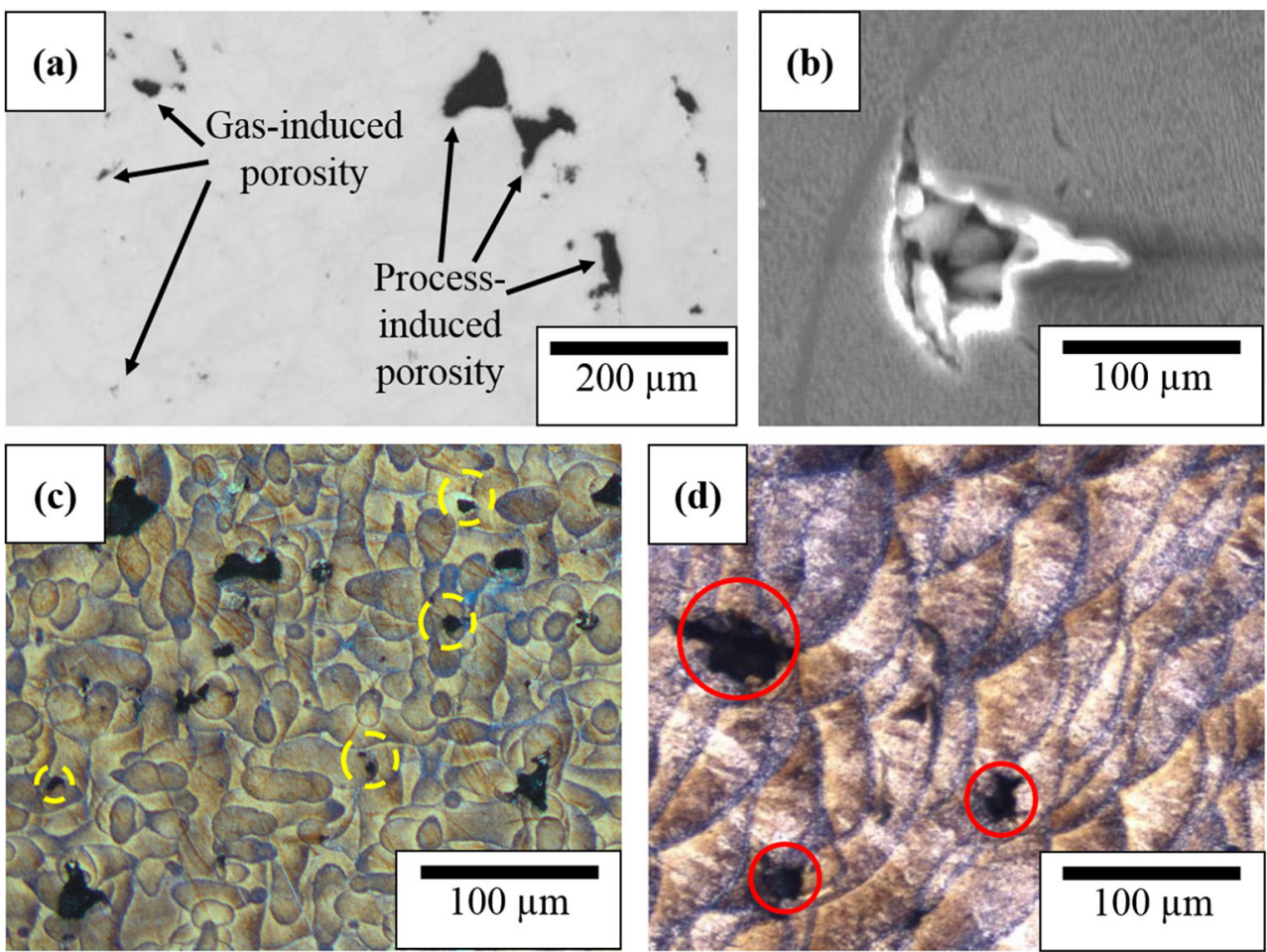



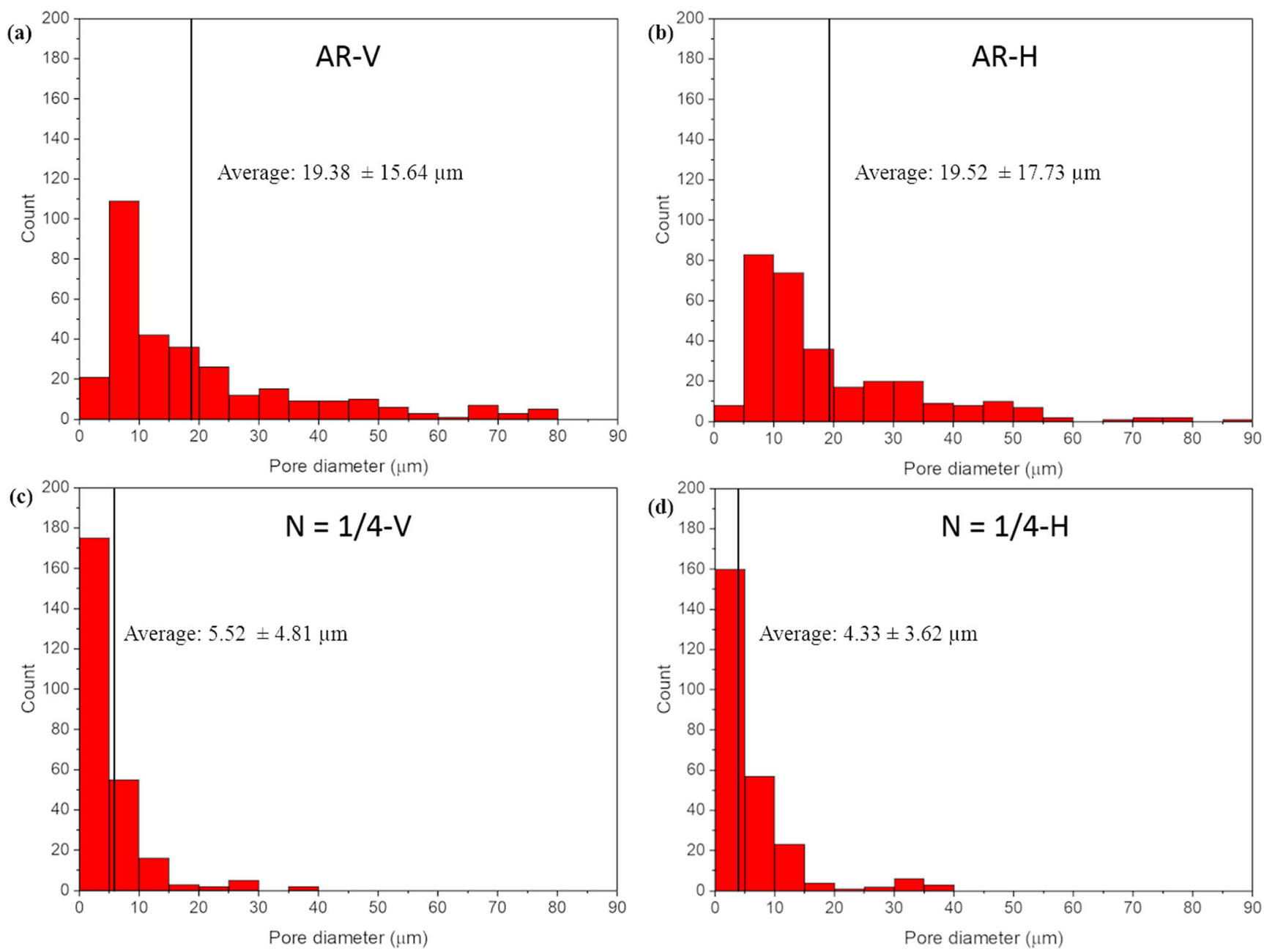

Fig. 3 Comparison of pore diameter in as-received samples a AR-V and b AR-H, and in samples processed through 1/4 HPT revolutions $\mathbf{c} 1 / 4-\mathrm{V}$ and $\mathbf{d}$ $1 / 4-\mathrm{H}$

significantly reduced pore diameters, with an average of 5.52 $\pm 4.81 \mu \mathrm{m}$ for $1 / 4-\mathrm{V}$ and $4.33 \pm 3.62 \mu \mathrm{m}$ for $1 / 4-\mathrm{H}$. Majority of the pores are in the sizes of $0-5 \mu \mathrm{m}$, and to a much lesser extent, between 5 and $15 \mu \mathrm{m}$. Only small amounts of pores in the sizes of 15-40 $\mu \mathrm{m}$ ( $<10$ counts) were observed for both $1 / 4-\mathrm{V}$ and $1 / 4-\mathrm{H}$ disks. Such dramatic reduction in porosity level was also observed by Yusuf et al. [20] in their study for SLM-fabricated and then HPT-processed 316L SS. These observations indicate that the HPT-imposed shear strain is able to effectively 'close' the pores, significantly reducing pore sizes for larger pores $(40-90 \mu \mathrm{m})$ and possibly eliminate smaller pores $(0-20 \mu \mathrm{m})$.

It is widely accepted that the generation and growth of pores in metals mainly depend on large levels of stress triaxiality under hydrostatic tension experienced, either under loading or during processing $[71,72]$. On the other hand, the application of hydrostatic pressure has been found to be crucial in eliminating porosity. For example, Nakasaki et al. [73] observed that rolling a steel billet in multiple passes via a constant hydrostatic pressure was able to eliminate the centre pores that initially existed in the steel billet. Wang et al. [74] found that the rate of pore closure during hot rolling of steels are influenced by rolling process parameters and the pore location relative to the rolling contact surfaces.

In addition to hydrostatic pressure, the application of shear strain also promotes the collapse and closure of pores, enabling a sound bonding to be achieved throughout the pores after they come into close contact atomically as the result of both hydrostatic pressure and shear strain $[75,76]$. Hydrostatic pressure and shear strain are two main features in severe plastic deformation (SPD) techniques to yield UFG microstructures and promote strong metallic bonding within the processed materials at both atomic and macroscopic scales $[77,78]$.

In addition, Qi et al. [37] systematically studied the generation and healing of porosity in HPT processing of pure $\mathrm{Cu}$ and explained the pore elimination mechanism in terms of grain refinement. The compressive pressure (from pushing the lower anvil to the upper anvil) and even small amount of torsional strain could cause the pores to collapse and stretch 
their internal surfaces together with the generation of UFG microstructures. Upon higher torsional strain, true submicron grains with clear grain boundaries start to form and the pores continuously elongate parallel to the shearing direction, fragmenting the pores and creating intimate atomic contact within the internal surface of the pores. Finally, at even higher torsional strain, internal friction within the internal pore surfaces creates strain gradients and high strain localisation, thus closing the pores. In this study, HPT has been proven as a very effective approach to reduce porosity via the strong metallic bonding that brings together and closes the pores as the result of the combination of hydrostatic pressure and torsional shear strain imposed.

\subsection{Phase composition and dislocation density}

XRD analysis Fig. 4 shows both $\mathrm{Al}$ and Si peaks are present in the AR-V and AR-H samples. A weak peak of $\mathrm{Mg}_{2} \mathrm{Si}$ intermetallic is also detected at $\sim 40^{\circ}$, which might precipitate from the diffusion of $\mathrm{Mg}$ and $\mathrm{Si}$ as the result of repeated heating cycles experienced during SLM processing [79]. Such heating cycles resemble the heat treatment process during the initial stages of age hardening of Al-Mg-Si alloys [80]. Upon HPT processing, broadening and shifting of peaks could be observed in both vertically and horizontally built samples (except for ( $\left.\begin{array}{lll}1 & 1 & 1\end{array}\right)$ orientation), similar to other studies on HPTprocessed metals $[81,82]$. These are mainly caused by lattice defects, e.g. internal microstrain, dislocations, small crystallite sizes and additional grain boundaries introduced via the HPTimposed torsional strains [83] (Fig. 4).

The dislocation density $\rho$ can be calculated from the lattice microstrain based on the following equation $[84,85]$ :

$\rho_{X R D}=\frac{2 \sqrt{3}\left\langle\varepsilon^{2}\right\rangle^{1 / 2}}{D_{c} b}$

where $D_{c}$ is the average crystallite size, referred to as coherently scattered domains (CSD), and $b$ is the burgers vector $(b=0.286 \mathrm{~nm}$ for $\mathrm{Al}[55])$. The values of $\left\langle\varepsilon^{2}>^{\frac{1}{2}}\right.$ and $D_{c}$ are obtained through the Rietveld refinement method applied in MAUD software, and the corresponding values of $\rho$ calculated based on Eq. 2 are shown in Table 3. It is revealed that the values of $\rho$ for as-received samples built in both orientations are already in the order of $1 \times 10^{14} \mathrm{~m}^{-2}$, much higher than $\times 10^{9}$ or $\times 10^{10} \mathrm{~m}^{-2}$ in conventional cast or wrought metals [86]. Such high $\rho$ values for as-built SLM samples are consistent with other studies on SLM AlSi10Mg [54] and pure iron [87], which are attributed to the numerous fine cellular structure colonies that store a large amount of dislocations, providing more sites to inhibit dislocation motions, and leading to relatively higher hardness compared to cast or wrought metals [86]. Upon HPT processing through 1 and 10 revolutions, the dislocation densities further increase to the region of $\sim 3.5-5 \times 10^{14} \mathrm{~m}^{-2}$. On the other hand, the crystallite sizes dramatically decrease from $\sim 280$ to $\sim 55-57 \mathrm{~nm}$ after 1 HPT revolution, before only slightly decreasing to $\sim 51-$ $52 \mathrm{~nm}$ after 10 HPT revolutions. The decrease in crystallite size is common in SPD-processed materials because the X-ray coherency is broken due to the small misorientations in the actual grains as the result of large shear strains applied during the process [83]. Therefore, the XRD analysis actually measures the crystallite sizes, rather than actual grain sizes.

For HPT-processed samples, the total dislocation density was calculated as the sum of geometrically necessary dislocations (GNDs) and statistically stored dislocations (SSDs). This is due to the presence of a strain gradient throughout the disk, with higher strains imposed at the edge compared to the centre region of the HPT-processed disk as the result of radial dependency, in accordance with Eq. 1 [81, 88].

\subsection{Microhardness measurements for as-received and HPT-processed samples}

Figures $5 \mathrm{a}$ and $\mathrm{b}$ show that the as-received samples exhibit reasonable homogeneity in the distribution of $\mathrm{HV}$ values across the diameter of the disks in both build orientations. It is worth noting that the HV values for SLM AlSi10Mg from this study (130-150 HV) are higher than that of their traditionally manufactured counterparts, e.g. $95-105 \mathrm{HV}$ in ashigh pressure die cast (HPDC) parts [89] and 64-70 HV in as-cast parts [90]. Higher hardness in SLM is also observed in various literatures and is commonly attributed to the finer microstructures attained as the result of significantly higher cooling rates/rapid solidification achieved in SLM due to the short laser-material contact time, thereby preventing recrystallisation or coarsening of the final microstructure $[1$, 41, 44, 91].

However, the HV values for AR-V (average: $\sim 145 \mathrm{HV}$ ) is slightly higher than that of AR-H (average: $\sim 136 \mathrm{HV}$ ), indicating anisotropy in SLM AlSi10Mg between both build orientations. Similar anisotropies are also observed in other AM materials, in which their properties differ with respect to build direction $[2,68,91,92]$. Several studies have identified possible causes for anisotropy in AM materials, including level of defects, residual stress, local heat transfer conditions, scan strategy, grain orientation, and to a lesser extent, crystallographic texture [22, 42]. For example, Yadroitsev et al. [93] attributed the lower elastic modulus in IN 625 specimens built vertically (parallel to z-axis) to the higher defect content due to larger concentration of residual stresses compared to the horizontal ones (parallel to $x-y$ plane). Frazier et al. [2] explained that lack-of-fusion pores is the reason for lower ductility of Ti alloys in the z-direction. Carroll et al. [92] observed lower ductility in Ti alloys built horizontally as a result of the orientation of prior- $\beta$ grains parallel to the build (z-direction). Chlebus et al. [94] ascribed the anisotropy in fracture modes 

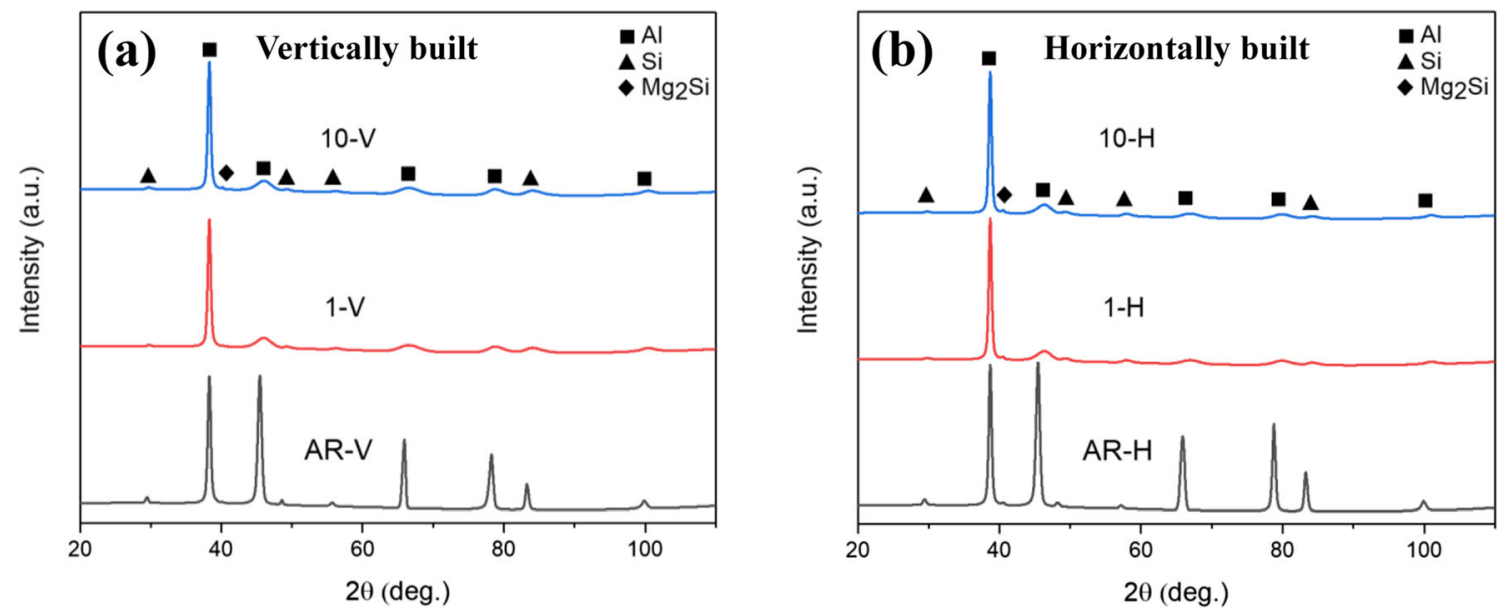

Fig. 4 XRD patterns for as-received and HPT-processed disks for samples built in the a vertical and $\mathbf{b}$ horizontal directions

and tensile properties of SLM IN 718 to the different orientations of the columnar grains with respect to loading directions. Accordingly, the lower hardness for AR-H samples than AR$\mathrm{V}$ could be attributed to the larger content of lack-of-fusion pores (process-induced porosity) at the melt pool boundaries (MPB) of AR-H compared to AR-V (Fig. 2c, d. This may lead to grain structure heterogeneity and structural discontinuities, which could weaken the bonding of the surrounding microstructure, thereby affecting the macroscopic mechanical behaviour [42].

In comparison to as-received samples, it is clear that the HV values in HPT-processed samples are significantly higher, increase with distance from the centre to the edge of the disk and with increased HPT revolutions. A relatively strong hardening was obtained after $1 / 4$ revolution, by a factor of $\sim 2$ for both sample orientations. It is also apparent that the majority hardness increment was achieved from 1/4 revolution, a common trend observed in many HPT-processed metals [95]. However, the increase in hardness is not homogeneous, with the central region exhibiting low $\mathrm{HV}$ values compared to the peripheral regions. This is expected because of the radial dependency of HPTinduced torsional strain in accordance with Eq. 1. Additional hardening was achieved with increasing number of revolutions and the highest HV value attained after 10 revolutions at the peripheral region was $218 \mathrm{HV}$ and $210 \mathrm{HV}$ for samples built

Table 3 Dislocation density parameters obtained through MAUD analysis of the XRD data

\begin{tabular}{lll}
\hline Sample & $\begin{array}{l}\text { Crystallite size, } \\
D_{c}(\mathrm{~nm})\end{array}$ & $\begin{array}{l}\text { Dislocation density, } \rho \\
\left(\times 10^{14} \mathrm{~m}^{-2}\right)\end{array}$ \\
\hline AR-V & $288 \pm 23$ & 1.23 \\
AR-H & $285 \pm 20$ & 1.18 \\
$1-\mathrm{V}$ & $57 \pm 4$ & 3.82 \\
$1-\mathrm{H}$ & $55 \pm 6$ & 3.75 \\
$10-\mathrm{V}$ & $52 \pm 2$ & 5.11 \\
$10-\mathrm{H}$ & $51 \pm 3$ & 4.92 \\
\hline
\end{tabular}

vertically and horizontally, respectively. However, the hardness distribution remains inhomogeneous across the disks even after 10 revolutions for samples built in both orientations, indicating that hardness saturation has not been achieved, even at extreme torsional strain imposed at the highest number of revolutions.

Nevertheless, the HV values are slightly higher in vertically built samples than that of horizontally built samples for all conditions, indicating that some level of anisotropy might still exist even after 10 revolutions of HPT processing. However, it is possible that this discrepancy is due to the grain orientation rather than porosity, since it is already established that the pores that were initially present in the as-received samples were significantly reduced after HPT.

The variation of $\mathrm{HV}$ values with equivalent strain $\varepsilon_{e q}$ calculated from Eq. 1 is shown in Fig. 6a, b. It is apparent that the hardness varies monotonically with the imposed strain. However, microhardness saturation is still not achieved for samples built in both directions even after 10 HPT revolutions. Other studies have also confirmed the difficulty of achieving complete homogeneity in some high-strength materials even after 20 revolutions [96-98]. They attributed this heterogeneity to the difficulty to attain true sub-micron or nano-scale grains at the central region or near the centre of the disks, even via extreme torsional strains.

Colour-coded contour maps are generated based on the microhardness measurements from the rectilinear grid mapping pattern to provide visualization of the distribution of individual HV values for the as-received and HPT-processed disks. Figure 7a shows the HV mapping for as-received samples, and Fig. 7b-e for HPT-processed samples through 1 and 10 revolutions. The colour-coded legend on the right of Fig. 7a defines the range of $\mathrm{HV}$ values represented by the different colours in the contour maps (from 140 to $220 \mathrm{HV}$ ).

A significant evolution of $\mathrm{HV}$ values could be observed after 1 HPT revolution for both 1-V (Fig. 7b) and 1-H (Fig. 7c) disks compared to that of the as-received samples (Fig. 7a). This is indicated by the transition from the blue region of low $\mathrm{HV}$ values 

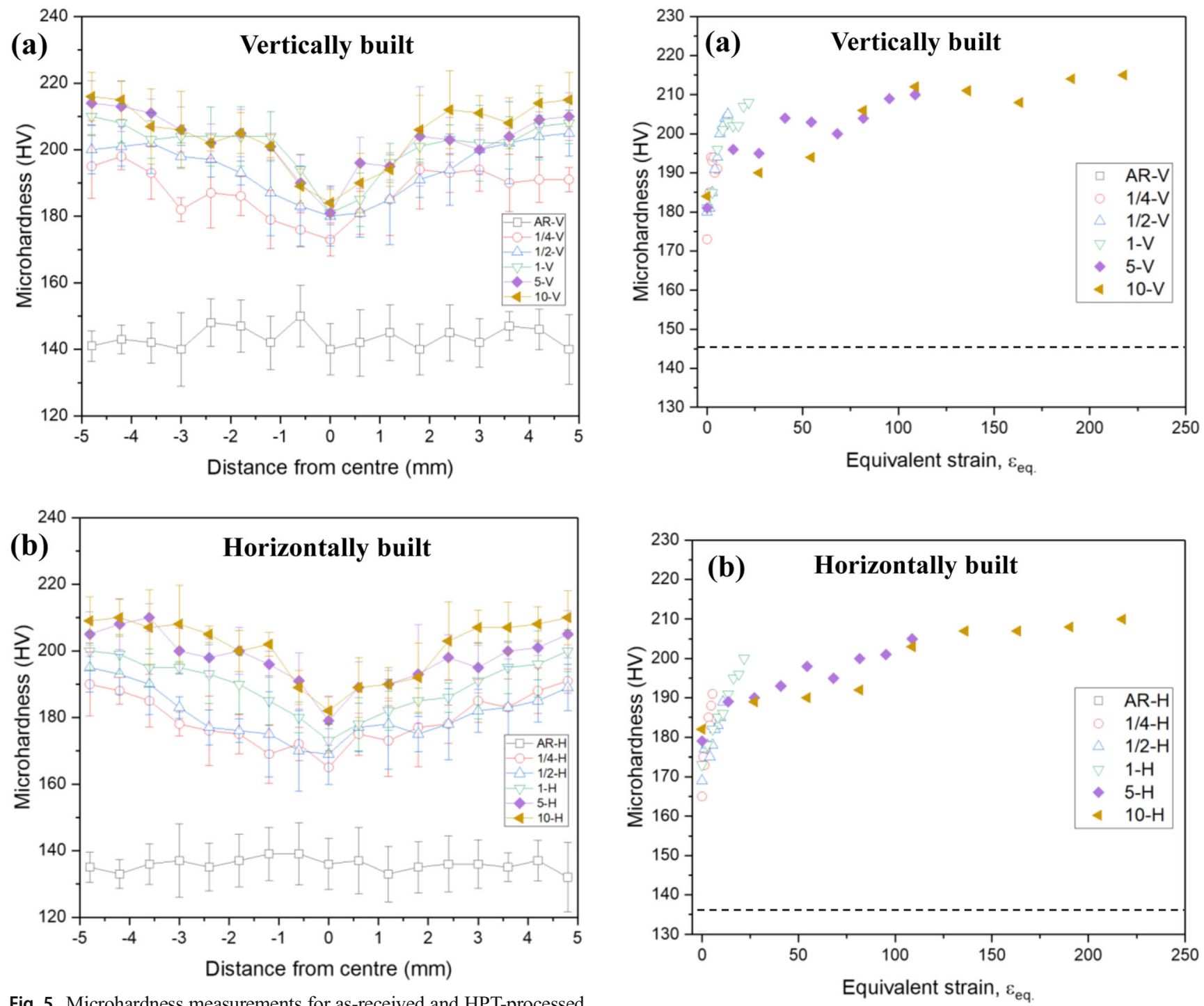

Fig. 5 Microhardness measurements for as-received and HPT-processed disks for samples built in the a vertical and $\mathbf{b}$ horizontal directions

to green-orange region of higher HV values. However, within the disks processed through 1 HPT revolution, Fig. 7b, c demonstrates that the sample built in vertical orientation shows higher HV values ( 190-205 HV) compared to that built in horizontal orientation ( 175-195 HV). These are indicated by the cooler colours in 1-H compared to $1-\mathrm{V}$, especially at the peripheral regions, with larger area in the centre of the disk extending over a width of $\sim 4 \mathrm{~mm}$ exhibiting lower HV values. The HV values further increase after 10 revolutions, as indicated by the transition from green-orange to green-red region in Fig. 7d, e. It is apparent that $10-\mathrm{V}$ disks possess higher $\mathrm{HV}$ values $(\sim 190-220 \mathrm{HV})$ than 10-H disks $(\sim 190-210 \mathrm{HV})$, as illustrated by the hotter colours at the peripheral regions and smaller area of cooler colours at the central region. Nevertheless, these contour maps further demonstrate that hardness saturation and microstructural homogeneity could still not be fully achieved, particularly at the central region even though the area with low HV values shrink with increasing torsional strain values.

Fig. 6 Plot of HV against equivalent strain, $\varepsilon_{e q}$, for as-received (dotted lines) and HPT-processed disks for samples built in the a vertical and $\mathbf{b}$ horizontal directions

\subsection{Microstructure observations for as-received samples}

Figures $8 \mathrm{a}$ and $\mathrm{b}$ show low-magnification OM images of the as-received samples built vertically (AR-V) and horizontally (AR-H), respectively, revealing distinct melt pool morphologies for samples built in different orientations. The AR-V sample (Fig. 8a) exhibits alternating bi-directional melt pool patterns corresponding to the scan strategy used in this study, while the AR-H sample (Fig. 8b) illustrates a fish scale (semi-circle) morphology corresponding to the layer-bylayer laser interaction with the powder bed. Good interand intra-layer overlapping is obtained for both samples, indicating a good bonding within a single layer and between successive layers [99]. 
Fig. 7 Microhardness distribution throughout the disk cross-section for a as-received samples, after 1 HPT revolution for $\mathbf{b} 1-\mathrm{V}$ and $\mathbf{c} 1-\mathrm{H}$, and after 10 HPT revolutions for $\mathbf{d} 10-\mathrm{V}$ and $\mathbf{e}$ $10-\mathrm{H}$

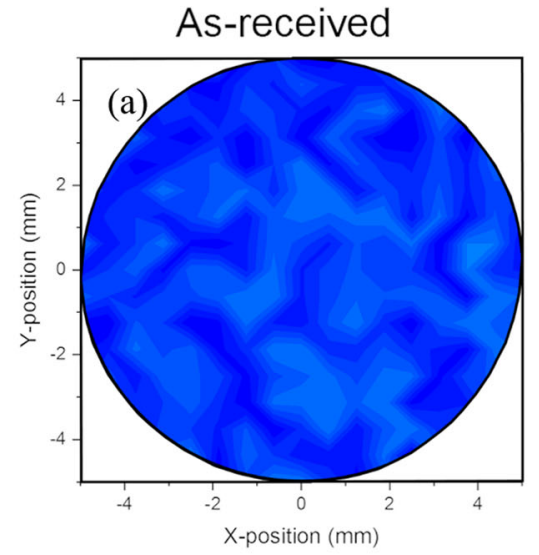

Microhardness (HV)
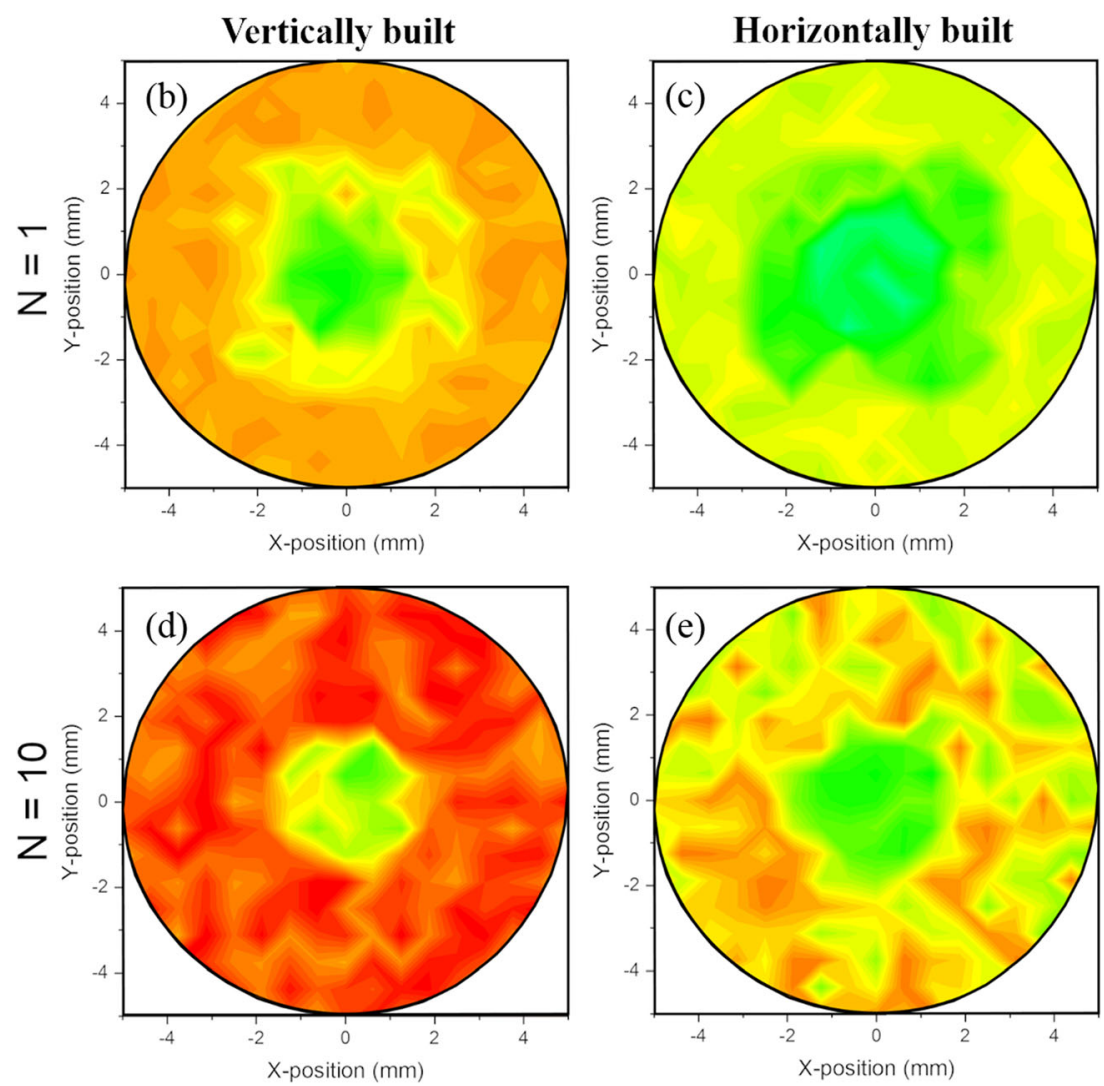

Figures $8 \mathrm{c}$ and $\mathrm{d}$ exhibit SEM images of AR-V and AR-H, respectively, while Fig. 8e shows a higher magnification SEM image of Fig. 8c, displaying much clearer SLM AlSi10Mg microstructures. They consist of very fine cellular-dendritic $\alpha$-Al matrix (size from $\sim 0.5$ to $1 \mu \mathrm{m}$ ) surrounded by thin fibrous eutectic Si network (thickness $<0.2 \mu \mathrm{m}$ ). Such fine microstructures are attributed to the rapid solidification of SLM process through repeated fast melting/cooling cycles, kinetically favouring the cellular solidification morphology and the extended solubility of Si into Al [22, 100]. Submicron Si particles that did not fuse together with the eutectic Si network could also be observed in the as-received samples.

The MPBs (dashed red lines in Fig. 8c, d) and the areas close to the MPBs have relatively coarser and more elongated microstructures, compared to the central region of the melt pools. This could be ascribed to the relatively different solidification rates throughout the melt pool, even though the solidification rates in SLM process is generally high $\left(10^{3}-10^{8} \mathrm{~K}^{\mathrm{s}-1}\right)$. In particular, the region around the MPBs and/or at the overlapping region between MPBs experiences longer laser-material interaction time due to the melting and re-melting of nearby powder bed in a single layer (AR-V) and of successive powder layers (AR-H). Hence, these regions could maintain at higher temperatures for longer periods, causing slower cooling rates and thus allowing the microstructures to coarsen. This phenomenon is common in SLM AlSi10Mg, which has been observed in other AM alloys [22, 41, 44]. 
Fig. 8 OM images of a AR-V and b AR-H samples, SEM images of c AR-V and d AR-H samples, and e SEM image showing typical microstructures of as-received SLM AlSi10Mg taken from ARV
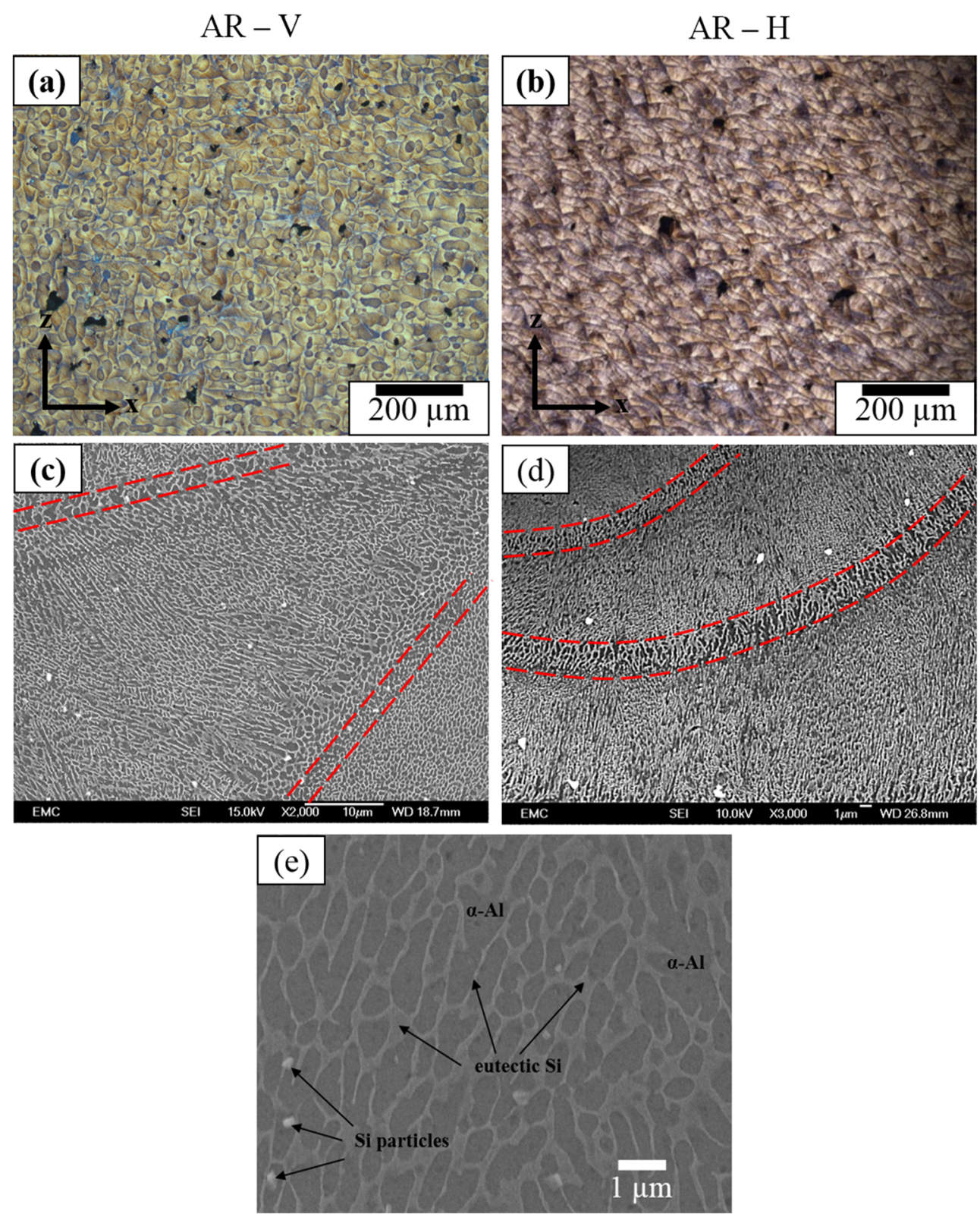

In addition, partially broken and coarsened eutectic Si network could also be observed at the MPBs (dashed red lines in Fig. 8c, d) due to the lower solidification rate at that region. $\mathrm{Mg}_{2} \mathrm{Si}$ precipitates have not been found from the SEM observations in this study, despite the presence of weak XRD peaks for this intermetallic.

\subsection{Microstructural evolution after HPT}

Figure 9 displays representative OM images of HPTprocessed disks through 1 and 10 revolutions for samples built in both orientations at the centre and edge ( $3 \mathrm{~mm}$ from centre) of the disks. These images show the evolution of melt pools as a result of HPT processing. The melt pools are observed to be slightly distorted and oriented at the centre after 1 revolution for 1-V (Fig. 9a) and 1-H (Fig. 9c) disks, compared to the shape and morphology of melt pools observed in AR-V (Fig. 8a) and AR-H (Fig. 8b). However, the melt pools at the edge of the disks become significantly sheared and extremely elongated for 1-V (Fig. 9b) and 1-H (Fig. 9d) disks, resulting in the loss of shape and morphology of the asreceived melt pools.

These observations provide clear indications of the inhomogeneous strain distribution across the diameter of the disks due to the radial dependency of shear strain imposed during HPT in accordance with Eq. 2. Based on this equation, the edges experience higher amounts of torsional strain compared to the centre of the disks, and this is confirmed via the heavily deformed melt pools at the edges after one turn corresponding to $\varepsilon_{e q}$ of $\sim 13.6$ (1-V, Fig. 9b and 1-H, Fig. 9d) compared to 
Fig. 9 OM images at the centre $(\mathbf{a}, \mathbf{c}, \mathbf{e}, \mathbf{g})$ and edge $(\mathbf{b}, \mathbf{d}, \mathbf{f}, \mathbf{h})$ of disks processed through 1 and 10 HPT revolutions for samples built on both vertical and horizontal orientations

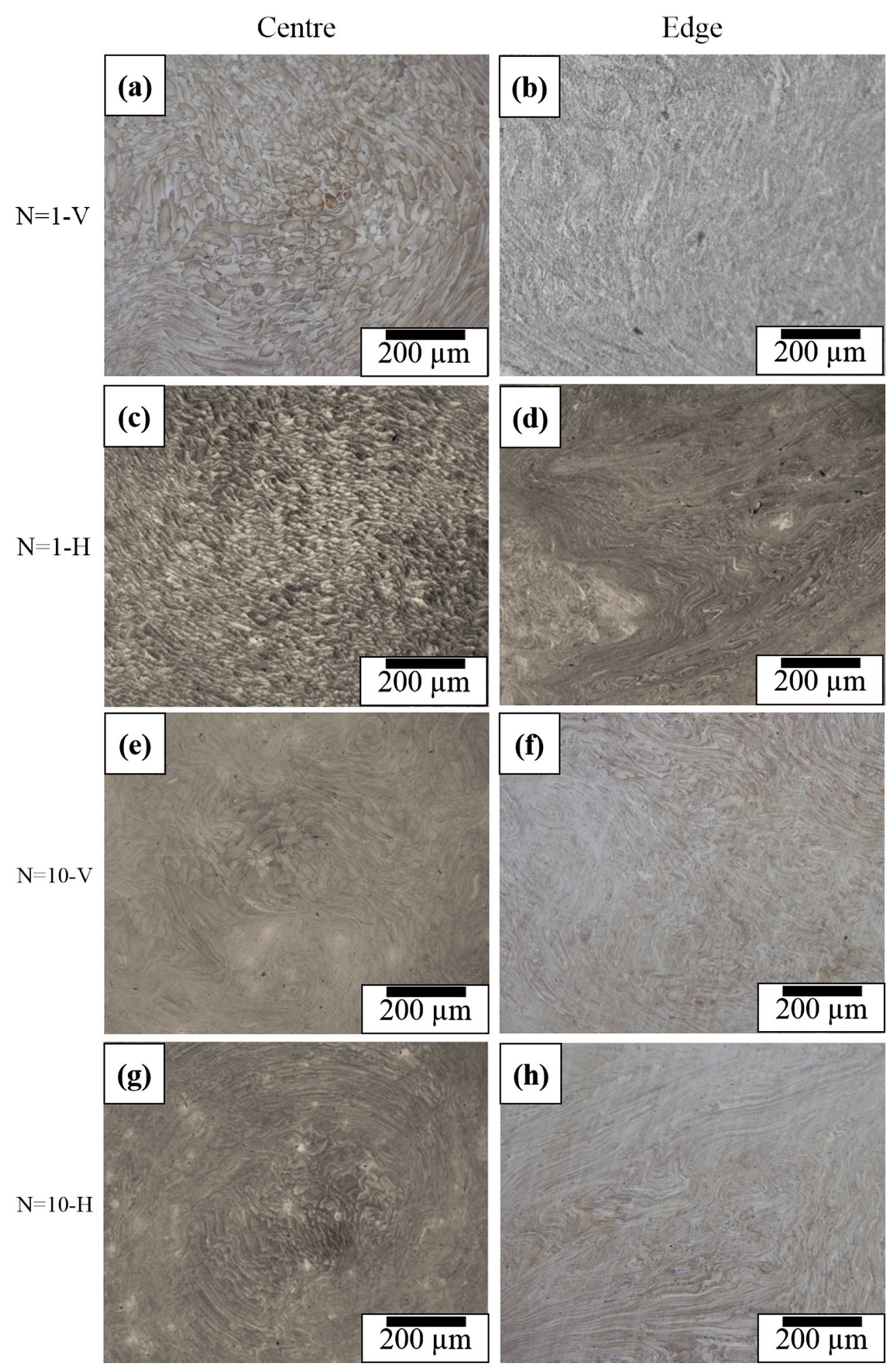

that at the centre (1-V, Fig. 9a, 1-H Fig. 9c). This is also in agreement with the higher $\mathrm{HV}$ values at the peripheral regions compared to the central region (Fig. 5a, b), thus affirming the application of microhardness measurements as an effective method to evaluate the extent of microstructural evolution in HPT-processed materials [101-103].
After 10 revolutions $\left(\varepsilon_{e q} \approx 136\right)$, the increased torsional strain at this stage further deformed the melt pools at the centre, such that they are extremely oriented, and the initial shape and morphology are no longer apparent although not completely eliminated as shown in Fig. 9e for 10-V and Fig. $9 \mathrm{~g}$ for $10-\mathrm{H}$. In addition, the shape and morphology of the 
Fig. 10 SEM images at the centre (a, c, e, g) and edge (b, d, f, h) of disks processed through 1 and 10 HPT revolutions for samples built on both vertical and horizontal orientations
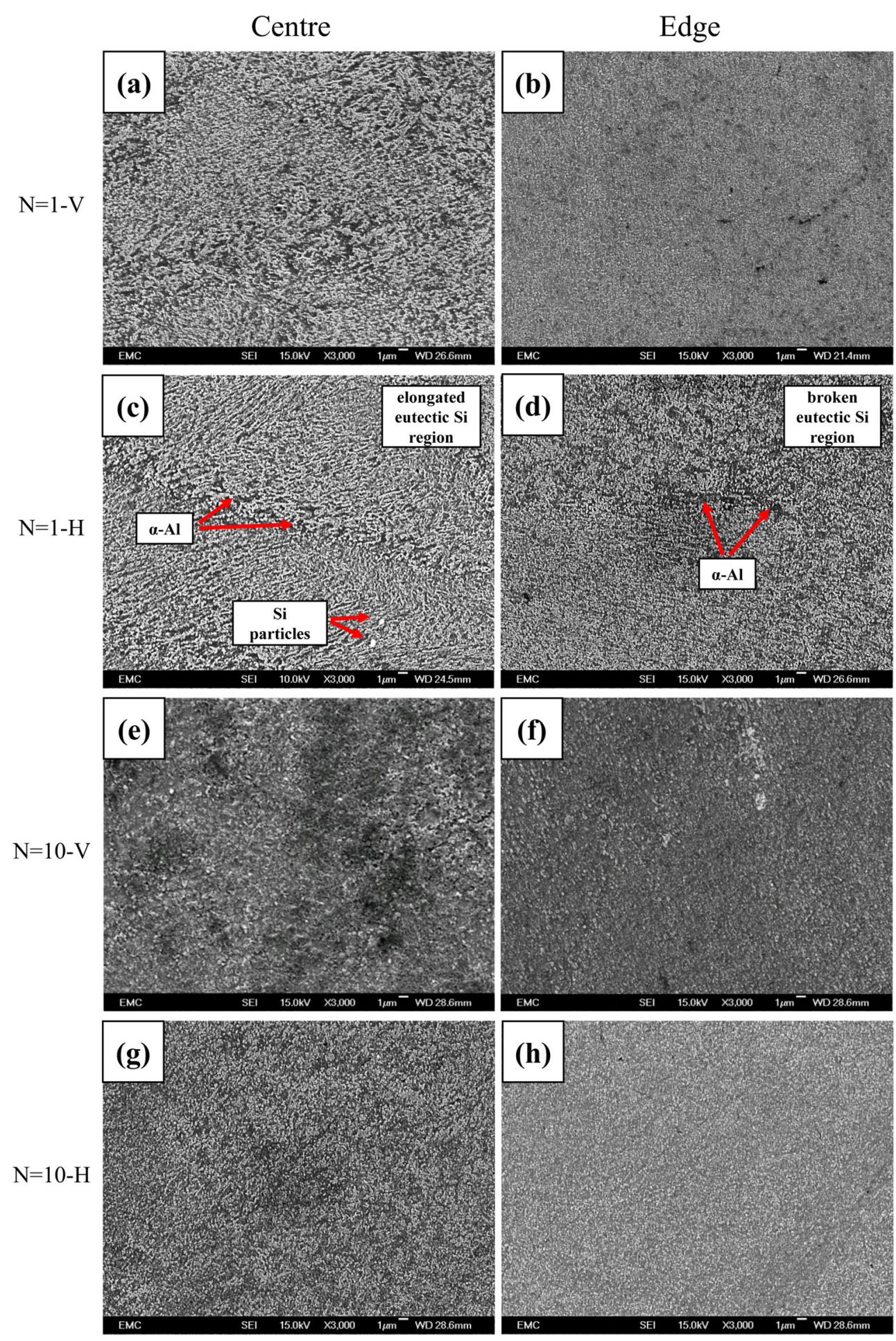

melt pools at the edges are completely lost for samples built in both directions (10-V, Fig. 10f and 10-H, Fig. 10h).

Figure 10 illustrates representative SEM images of HPTprocessed disks through 1 and 10 revolutions for samples built in both orientations at the centre and edge ( $3 \mathrm{~mm}$ from centre) of the disks. After HPT processing through 1 revolution, at the centre of the disks (1-V, Fig. 10a and 1-H, Fig. 10c), the cellular-dendritic $\alpha$-Al matrix was compressed, while the eutectic Si network was refined and elongated. Some of the eutectic Si networks were also broken into fine Si particles. On the other hand, most of the eutectic Si networks are broken into fine Si particles that are dispersed more uniformly in the Al matrix at the edge of the disks (1-V, Fig. 10b and 1-H, Fig. 10d). After 10 revolutions, Fig. $10 \mathrm{e}-\mathrm{h}$ exhibits the complete 

diameter measured through ImageJ software
Table 4 Average cell

\begin{tabular}{lll}
\hline Sample & Centre $(\mu \mathrm{m})$ & Edge $(\mu \mathrm{m})$ \\
\hline AR-V & $0.75 \pm 0.15$ & - \\
AR-H & $0.74 \pm 0.21$ & - \\
$1-\mathrm{V}$ & $0.50 \pm 0.05$ & $0.38 \pm 0.11$ \\
$1-\mathrm{H}$ & $0.51 \pm 0.08$ & $0.36 \pm 0.13$ \\
\hline
\end{tabular}

breakage of the eutectic Si network into fine Si particles. At this stage, the size of the fine Si particles significantly decreases, while the volume fraction obviously increases and more homogeneously distributed throughout the Al matrix compared to that after 1 revolution. This is because of the continuous breakage of the eutectic Si network after 10 HPT revolutions, resulting in the formation of new fine Si particles.

The observation of eutectic Si network breakage into fine Si particles upon increased HPT-imposed torsional strain is consistent with other studies on the HPT processing of traditional cast Al-7Si alloy [58, 104], which can be attributed to two factors $[104,105]$ : (i) increase in temperature due to friction generated during HPT straining may lead to nucleation and growth of fine Si particles or (ii) the severe plastic deformation that could cause fragmentation and redistribution of larger Si particles into smaller segments in the Al matrix.

To evaluate the extent of the microstructural evolution due to HPT, ImageJ software was used to characterize the cellulardendritic network observed via SEM. Values for average diameter of the cells in the as-received and HPT-processed disks are listed in Table 4 for samples built in both directions. It could be seen that the average cell diameter for as-received samples is $\sim 0.75 \mu \mathrm{m}$, which then decreases to $\sim 0.50 \mu \mathrm{m}$ (centre) and $\sim 0.37 \mu \mathrm{m}$ (edge) after $1 \mathrm{HPT}$ revolution for samples built in both orientations.

On the other hand, Fig. 11 shows the evolution of the circularity of the cellular-dendritic network in as-received and HPT-processed disks for samples built in the horizontal orientation. Values closer to 1 indicate increasingly circular shape, while values closer to 0 represents increasingly elongated morphology. The circularity of the cells for the as-received sample ranges from 0.5 to 0.95 (average: $0.756 \pm 0.07$ ) and
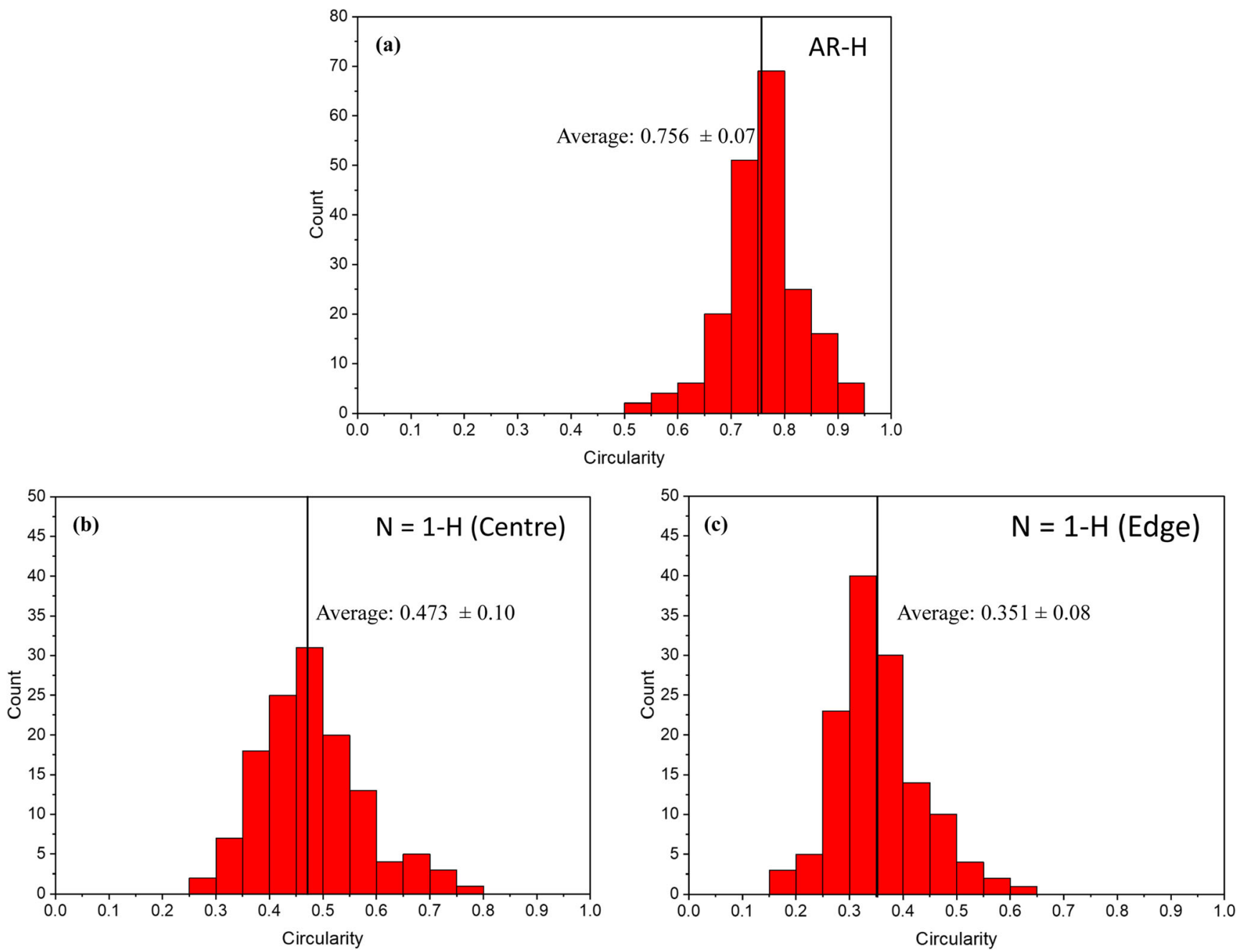

Fig. 11 Circularity of the cellular-dendritic structure for as-received and HPT-processed disks in horizontally built samples 
after 1 HPT revolution, decreases to $0.25-0.75$ (average 0.473 \pm 0.10 ) at the centre and to $0.15-0.60$ (average $0.351 \pm 0.08$ ) at the edge of the disks. The lower average circularity at the edge compared to at the centre of the disks after 1 HPT revolution (by $\sim 25 \%$ ) further confirms the radial influence of the torsional strain imposed via HPT. The diameter and circularity of the cellular-dendritic structure could not be measured after 10 HPT revolutions because most of the eutectic Si networks are broken down into finer Si particles. Nevertheless, the reduced average diameter and circularity of the cells with increased HPT revolutions are attributed to the large shear strains due to the HPT-induced torsional strain, which have also been observed by Yusuf et al. in their study of 316L SS fabricated by SLM and then processed by HPT [20].

\section{Conclusion}

The evolution of microstructure and microhardness of AlSi10Mg fabricated by SLM in both vertical and horizontal orientations and then processed by HPT through $1 / 4$ to 10 revolutions were investigated through OM, SEM, microhardness measurements, and XRD. The main conclusions can be drawn as follows:

1. Although both spherical (gas-induced) and non-spherical (process-induced) pores are present in vertically built samples, process-induced porosity is more apparent in horizontally built samples.

2. The microstructure of as-received SLM AlSi10Mg consists of cellular-dendritic Al matrix surrounded by fine, fibrous eutectic Si phase network for samples built in both build orientation.

3. The lower HV values in horizontally built samples are attributed to the larger fraction of process-induced pores at the fish-scale MPB, compared to vertically built samples.

4. HPT processing for $1 / 4$ revolution significantly reduced the porosity by $\sim 94 \%$ compared to the as-received samples.

5. HPT processing significantly increases the hardness of the alloy, but microstructural homogeneity was not achieved even after 10 HPT revolutions.

6. As the number of HPT revolutions increase, the cellulardendritic $\mathrm{Al}$ matrix becomes increasingly refined and elongated, while the eutectic Si network is continuously broken into fine Si particles and dispersed uniformly throughout the Al Matrix.

Acknowledgments S. Mohd Yusuf would like to thank the Faculty of Engineering and Physical Sciences, University of Southampton, UK for providing a studentship for his $\mathrm{PhD}$ study.

\section{Compliance with ethical standards}

Conflict of interest The authors declare that they have no conflict of interest.

Open Access This article is licensed under a Creative Commons Attribution 4.0 International License, which permits use, sharing, adaptation, distribution and reproduction in any medium or format, as long as you give appropriate credit to the original author(s) and the source, provide a link to the Creative Commons licence, and indicate if changes were made. The images or other third party material in this article are included in the article's Creative Commons licence, unless indicated otherwise in a credit line to the material. If material is not included in the article's Creative Commons licence and your intended use is not permitted by statutory regulation or exceeds the permitted use, you will need to obtain permission directly from the copyright holder. To view a copy of this licence, visit http://creativecommons.org/licenses/by/4.0/.

\section{References}

1. Gu DD, Meiners W, Wissenbach K, Poprawe R (2012) Laser additive manufacturing of metallic components: materials, processes and mechanisms. Int Mater Rev 57:133-164. https://doi. org/10.1179/1743280411Y.0000000014

2. Frazier WE (2014) Metal additive manufacturing: a review. J Mater Eng Perform 23:1917-1928. https://doi.org/10.1007/ s11665-014-0958-Z

3. Buchbinder D, Meiners W, Wissenbach K, Poprawe R (2015) Selective laser melting of aluminum die-cast alloy-correlations between process parameters, solidification conditions, and resulting mechanical properties. J Laser Appl 27:S29205. https:// doi.org/10.2351/1.4906389

4. Rao H, Giet S, Yang K et al (2016) The influence of processing parameters on aluminium alloy A357 manufactured by selective laser melting. Mater Des 109:334-346. https://doi.org/10.1016/j. matdes.2016.07.009

5. Ma M, Wang Z, Zeng X (2017) A comparison on metallurgical behaviors of $316 \mathrm{~L}$ stainless steel by selective laser melting and laser cladding deposition. Mater Sci Eng A 685:265-273. https:// doi.org/10.1016/j.msea.2016.12.112

6. Sun Z, Tan X, Tor SB, Yeong WY (2016) Selective laser melting of stainless steel 316L with low porosity and high build rates. Mater Des 104:197-204. https://doi.org/10.1016/j.matdes.2016. 05.035

7. Wang D, Song C, Yang Y, Bai Y (2016) Investigation of crystal growth mechanism during selective laser melting and mechanical property characterization of $316 \mathrm{~L}$ stainless steel parts. Mater Des 100:291-299. https://doi.org/10.1016/j.matdes.2016.03.111

8. Geiger F, Kunze K, Etter T (2016) Tailoring the texture of IN738LC processed by selective laser melting (SLM) by specific scanning strategies. Mater Sci Eng A 661:240-246. https://doi. org/10.1016/j.msea.2016.03.036

9. Sun SH, Hagihara K, Nakano T (2018) Effect of scanning strategy on texture formation in $\mathrm{Ni}-25$ at.\%Mo alloys fabricated by selective laser melting. Mater Des 140:307-316. https://doi.org/10. 1016/j.matdes.2017.11.060

10. Kunze K, Etter T, Jürgen G, Shklover V (2014) Texture, anisotropy in microstructure and mechanical properties of IN738LC alloy processed by selective laser melting (SLM). Mater Sci Eng A 620. https://doi.org/10.1016/j.msea.2014.10.003

11. Biamino S, Penna A, Ackelid U et al (2011) Electron beam melting of Ti-48Al-2Cr-2 $\mathrm{Nb}$ alloy: microstructure and mechanical 
properties investigation. Intermetallics 19:776-781. https://doi. org/10.1016/j.intermet.2010.11.017

12. Song B, Dong S, Liao H, Coddet C (2012) Process parameter selection for selective laser melting of Ti6Al4V based on temperature distribution simulation and experimental sintering. Int $\mathrm{J}$ Adv Manuf Technol 61:967-974. https://doi.org/10.1007/s00170-0113776-6

13. Xu W, Brandt M, Sun S et al (2015) Additive manufacturing of strong and ductile $\mathrm{Ti}-6 \mathrm{Al}-4 \mathrm{~V}$ by selective laser melting via in situ martensite decomposition. Acta Mater 85:74-84. https://doi.org/ 10.1016/j.actamat.2014.11.028

14. Leary M, Mazur M, Elambasseril J et al (2016) Selective laser melting (SLM) of AlSi12Mg lattice structures. Mater Des 98: 344-357. https://doi.org/10.1016/j.matdes.2016.02.127

15. Manfredi D, Bidulský R (2017) Laser powder bed fusion of aluminum alloys. Acta Metall Slovaca 23:276. https://doi.org/10. 12776/ams.v23i3.988

16. Li Y, Gu D (2014) Parametric analysis of thermal behavior during selective laser melting additive manufacturing of aluminum alloy powder. Mater Des 63:856-867. https://doi.org/10.1016/j.matdes. 2014.07.006

17. Li XP, Wang XJ, Saunders M et al (2015) A selective laser melting and solution heat treatment refined Al-12Si alloy with a controllable ultrafine eutectic microstructure and $25 \%$ tensile ductility. Acta Mater 95:74-82. https://doi.org/10.1016/j.actamat.2015.05. 017

18. Suryawanshi J, Prashanth KG, Scudino S et al (2016) Simultaneous enhancements of strength and toughness in an Al12Si alloy synthesized using selective laser melting. Acta Mater 115:285-294. https://doi.org/10.1016/j.actamat.2016.06.009

19. Trelewicz JR, Halada GP, Donaldson OK, Manogharan G (2016) Microstructure and corrosion resistance of laser additively manufactured 316L stainless steel. Jom 68:850-859. https://doi. org/10.1007/s11837-016-1822-4

20. Mohd Yusuf S, Nie M, Chen Y et al (2018) Microstructure and corrosion performance of $316 \mathrm{~L}$ stainless steel fabricated by selective laser melting and processed through high-pressure torsion. J Alloys Compd 763:360-375. https://doi.org/10.1016/j.jallcom. 2018.05.284

21. Geenen K, Röttger A, Theisen W (2017) Corrosion behavior of 316L austenitic steel processed by selective laser melting, hotisostatic pressing, and casting. Mater Corros 9999:1-12. https:// doi.org/10.1002/maco.201609210

22. Trevisan F, Calignano F, Lorusso $\mathrm{M}$ et al (2017) On the selective laser melting (SLM) of the AlSi10Mg alloy: process, microstructure, and mechanical properties. Materials (Basel) 10. https://doi. org/10.3390/ma10010076

23. Herzog D, Seyda V, Wycisk E, Emmelmann C (2016) Additive manufacturing of metals. Acta Mater 117:371-392. https://oi. org/10.1016/j.actamat.2016.07.019

24. Gu D, Hagedorn Y-C, Meiners W et al (2012) Densification behavior, microstructure evolution, and wear performance of selective laser melting processed commercially pure titanium. Acta Mater 60:3849-3860. https://doi.org/10.1016/j.actamat.2012.04. 006

25. Yusuf SM, Gao N (2017) Influence of energy density on metallurgy and properties in metal additive manufacturing. Mater Sci Technol 33:1269-1289. https://doi.org/10.1080/02670836.2017. 1289444

26. Li Y, Chen K, Tamura N (2018) Mechanism of heat affected zone cracking in Ni-based superalloy DZ125L fabricated by laser 3D printing technique. Mater Des 150:171-181. https://doi.org/10. 1016/j.matdes.2018.04.032

27. Popovich VA, Borisov EV, Popovich AA et al (2017) Impact of heat treatment on mechanical behaviour of Inconel 718 processed with tailored microstructure by selective laser melting. Mater Des 131:12-22. https://doi. org/10.1016/j.matdes.2017.05.065

28. Lavery NP, Cherry J, Mehmood S et al (2017) Effects of hot isostatic pressing on the elastic modulus and tensile properties of 316L parts made by powder bed laser fusion. Mater Sci Eng A 693:186-213. https://doi.org/10.1016/j.msea.2017.03.100

29. Azushima A, Kopp R, Korhonen A et al (2008) Severe plastic deformation (SPD) processes for metals. CIRP Ann Manuf Technol 57:716-735. https://doi.org/10.1016/j.cirp.2008.09.005

30. Edalati K, Horita Z (2016) A review on high-pressure torsion (HPT) from 1935 to 1988. Mater Sci Eng A 652:325-352. https://doi.org/10.1016/j.msea.2015.11.074

31. Abramova MM, Enikeev NA, Valiev RZ et al (2014) Grain boundary segregation induced strengthening of an ultrafinegrained austenitic stainless steel. Mater Lett 136:349-352. https://doi.org/10.1016/j.matlet.2014.07.188

32. Valiev RZ, Langdon TG (2006) Principles of equal-channel angular pressing as a processing tool for grain refinement. Prog Mater Sci 51:881-981. https://doi.org/10.1016/j.pmatsci.2006.02.003

33. Gao N, Wang CT, Wood RJK, Langdon TG (2012) Tribological properties of ultrafine-grained materials processed by severe plastic deformation. J Mater Sci 47:4779-4797. https://doi.org/10. 1007/s10853-011-6231-Z

34. Zheng ZJ, Gao Y, Gui Y, Zhu M (2012) Corrosion behaviour of nanocrystalline 304 stainless steel prepared by equal channel angular pressing. Corros Sci 54:60-67. https://doi.org/10.1016/j. corsci.2011.08.049

35. Sakai G, Horita Z, Langdon TG (2005) Grain refinement and superplasticity in an aluminum alloy processed by high-pressure torsion. Mater Sci Eng A 393:344-351. https://doi.org/10.1016/j. msea.2004.11.007

36. Furukawa M, Horita Z, Nemoto M, Langdon TG (2001) Review: processing of metals by equal-channel angular pressing. J Mater Sci 36:2835-2843. https://doi.org/10.1023/a:1017932417043

37. Qi Y, Kosinova A, Kilmametov AR et al (2018) Generation and healing of porosity in high purity copper by high-pressure torsion. Mater Charact 145:1-9. https://doi.org/10.1016/j.matchar.2018. 08.023

38. Wilde G, Zehetbauer M, Wegner M et al (2011) Deformation induced percolating porosity in high pressure torsioned (HPT) copper. Mater Sci Forum 702-703:105-108. https://doi.org/10. 4028/www.scientific.net/msf.702-703.105

39. Read N, Wang W, Essa K, Attallah MM (2015) Selective laser melting of AlSi10Mg alloy: process optimisation and mechanical properties development. Mater Des 65:417-424. https://doi.org/ 10.1016/j.matdes.2014.09.044

40. Li W, Li S, Liu J et al (2016) Effect of heat treatment on AlSi10Mg alloy fabricated by selective laser melting: microstructure evolution, mechanical properties and fracture mechanism. Mater Sci Eng A 663:116-125. https://doi.org/10.1016/j.msea.2016.03.088

41. Asgari H, Baxter C, Hosseinkhani K, Mohammadi M (2017) On microstructure and mechanical properties of additively manufactured AlSi10Mg 200C using recycled powder. Mater Sci Eng A 707:148-158. https://doi.org/10.1016/j.msea.2017.09. 041

42. Tang M, Pistorius PC (2017) Anisotropic mechanical behavior of AlSi10Mg parts produced by selective laser melting. Jom 69:516 522. https://doi.org/10.1007/s11837-016-2230-5

43. Mao F, Yan G, Xuan Z et al (2015) Effect of trace La addition on the microstructures and mechanical properties of A356 (Al-7Si$0.35 \mathrm{Mg}$ ) aluminum aluminum alloys. J Alloys Compd 650:896906. https://doi.org/10.1016/j.jallcom.2015.06.266

44. Liu X, Zhao C, Zhou X et al (2019) Microstructure of selective laser melted AlSi10Mg alloy. Mater Des 168:1-9. https://doi.org/ 10.1016/j.matdes.2019.107677 
45. McDonald SD, Nogita K, Dahle AK (2004) Eutectic nucleation in Al-Si alloys. Acta Mater 52:4273-4280. https://doi.org/10.1016/j. actamat.2004.05.043

46. Lu L, Nogita K, Dahle AK (2005) Combining Sr and Na additions in hypoeutectic Al-Si foundry alloys. Mater Sci Eng A 399:244 253. https://doi.org/10.1016/j.msea.2005.03.091

47. Karaköse E, Keskin M (2009) Effect of solidification rate on the microstructure and microhardness of a melt-spun Al-8Si-1 Sb alloy. J Alloys Compd 479:230-236. https://doi.org/10.1016/j. jallcom.2009.01.006

48. Kempen K, Thijs L, Van Humbeeck J, Kruth J-P (2015) Processing AlSi10Mg by selective laser melting: parameter optimisation and material characterisation. Mater Sci Technol 31. https://doi.org/10.1179/1743284714Y.0000000702

49. Wei P, Wei Z, Chen $Z$ et al (2017) The AlSi10Mg samples produced by selective laser melting: single track, densification, microstructure and mechanical behavior. Appl Surf Sci 408:38-50. https://doi.org/10.1016/j.apsusc.2017.02.215

50. Aboulkhair NT, Maskery I, Tuck C et al (2016) The microstructure and mechanical properties of selectively laser melted AlSi10Mg: the effect of a conventional T6-like heat treatment. Mater Sci Eng A 667:139-146. https://doi.org/10.1016/j.msea. 2016.04.092

51. Chou R, Ghosh A, Chou SC et al (2017) Microstructure and mechanical properties of Al10SiMg fabricated by pulsed laser powder bed fusion. Mater Sci Eng A 689:53-62. https://doi.org/10. 1016/j.msea.2017.02.023

52. Lam LP, Zhang DQ, Liu ZH, Chua CK (2015) Phase analysis and microstructure characterisation of AlSi10Mg parts produced by selective laser melting. Virtual Phys Prototyp 10:207-215. https://doi.org/10.1080/17452759.2015.1110868

53. Kempen K, Thijs L, Van Humbeeck J, Kruth JP (2012) Mechanical properties of AlSil0Mg produced by selective laser melting. Phys Procedia 39:439-446. https://doi.org/10.1016/j. phpro.2012.10.059

54. Hadadzadeh A, Baxter C, Amirkhiz BS, Mohammadi M (2018) Strengthening mechanisms in direct metal laser sintered AlSi10Mg: comparison between virgin and recycled powders. Addit Manuf 23:108-120. https://doi.org/10.1016/j.addma.2018. 07.014

55. Chen B, Moon SK, Yao X et al (2017) Strength and strain hardening of a selective laser melted AlSi10Mg alloy. Scr Mater 141: 45-49. https://doi.org/10.1016/j.scriptamat.2017.07.025

56. Li XP, Ji G, Chen Z et al (2017) Selective laser melting of nanoTiB2 decorated AlSi10Mg alloy with high fracture strength and ductility. Acta Mater. https://doi.org/10.1016/j.actamat.2017.02. 062

57. Wang X, Nie M, Wang CT et al (2015) Microhardness and corrosion properties of hypoeutectic Al-7Si alloy processed by highpressure torsion. Mater Des 83:193-202. https://doi.org/10.1016/j. matdes.2015.06.018

58. Mungole T, Nadammal N, Dawra K, Kumar P, Kawasaki M, Langdon TG (2013) Evolution of microhardness and microstructure in a cast $\mathrm{Al}-7 \% \mathrm{Si}$ alloy during high-pressure torsion. J Mater Sci 48:4671-4680. https://doi.org/10.1007/s10853-012-7061-3

59. El Aal MIA, Kim HS (2014) Wear properties of high pressure torsion processed ultrafine grained Al-7\% Si alloy. Mater Des 53: 373-382. https://doi.org/10.1016/j.matdes.2013.07.045

60. Gunenthiram V, Peyre P, Schneider M et al (2017) Experimental analysis of spatter generation and melt-pool behavior during the powder bed laser beam melting process. J Mater Process Technol 251:376-386. https://doi.org/10.1016/j.jmatprotec.2017.08.012

61. Ali H, Ghadbeigi H, Mumtaz K (2018) Effect of scanning strategies on residual stress and mechanical properties of selective laser melted Ti6A14V. Mater Sci Eng A 712:175-187. https://doi.org/ 10.1016/j.msea.2017.11.103
62. Kawasaki M, Figueiredo RB, Langdon TG (2011) An investigation of hardness homogeneity throughout disks processed by highpressure torsion. Acta Mater 59:308-316. https://doi.org/10.1016/ j.actamat.2010.09.034

63. Wang CT, Gao N, Gee MG et al (2012) Effect of grain size on the micro-tribological behavior of pure titanium processed by highpressure torsion. Wear 280-281:28-35. https://doi.org/10.1016/j. wear.2012.01.012

64. Nie M, Wang CT, Qu M, Gao N, Wharton JA, Langdon TG (2014) The corrosion behaviour of commercial purity titanium processed by high-pressure torsion. J Mater Sci 49:2824-2831. https://doi.org/10.1007/s10853-013-7988-z

65. Lutterotti L, Gialanella S (1998) X-ray diffraction characterization of heavily deformed metallic specimens. Acta Mater 46:101-110

66. Mccusker LB, Von Dreele RB, Cox DE et al (1999) Rietveld refinement guidelines. J Appl Crystallogr 32:36-50. https://doi. org/10.1107/S0021889898009856

67. Young RA, Wiles DB (1982) Profile shape functions in Rietveld refinements. J Appl Crystallogr 15:430-438

68. Sames WJ, List FA, Pannala S et al (2016) The metallurgy and processing science of metal additive manufacturing. Int Mater Rev 61:1-46. https://doi.org/10.1080/09506608.2015.1116649

69. Sames WJJ, Medina F, Peter WHH et al (2014) Effect of process control and powder quality on IN 718 produced using electron beam melting. In: 8th international symposium on Superalloy 718 and derivatives. Wiley-Blackwell, Pittsburgh, pp 409-423

70. Hebert RJ (2016) Viewpoint: metallurgical aspects of powder bed metal additive manufacturing. J Mater Sci 51:1165-1175. https:// doi.org/10.1007/s10853-015-9479-x

71. Rice JR, Tracey DM (1969) On the ductile enlargement of voids in triaxial stress fields*. J Mech Phys Solids 17:201-217. https://doi. org/10.1016/0022-5096(69)90033-7

72. Xue L (2007) Damage accumulation and fracture initiation in uncracked ductile solids subject to triaxial loading. Int J Solids Struct 44:5163-5181. https://doi.org/10.1016/j.ijsolstr.2006.12. 026

73. Nakasaki M, Takasu I, Utsunomiya H (2006) Application of hydrostatic integration parameter for free-forging and rolling. $\mathrm{J}$ Mater Process Technol 177:521-524. https://doi.org/10.1016/j. jmatprotec.2006.04.102

74. Wang A, Thomson PF, Hodgson PD (1996) A study of pore closure and welding in hot rolling process. J Mater Process Technol 60:95-102. https://doi.org/10.1016/0924-0136(96)02313-8

75. Saby M, Bouchard PO, Bernacki M (2015) Void closure criteria for hot metal forming: a review. J Manuf Process 19:239-250. https://doi.org/10.1016/j.jmapro.2014.05.006

76. Zhang XX, Cui ZS, Chen W, Li Y (2009) A criterion for void closure in large ingots during hot forging. J Mater Process Technol 209:1950-1959. https://doi.org/10.1016/j.jmatprotec.2008.04.051

77. Langdon TG (2013) Twenty-five years of ultrafine-grained materials: achieving exceptional properties through grain refinement. Acta Mater 61:7035-7059. https://doi.org/10.1016/j.actamat. 2013.08.018

78. Estrin Y, Vinogradov A (2013) Extreme grain refinement by severe plastic deformation: a wealth of challenging science. Acta Mater 61:782-817. https://doi.org/10.1016/j.actamat.2012.10.038

79. Hadadzadeh A, Amirkhiz BS, Mohammadi M (2019) Contribution of $\mathrm{Mg} 2 \mathrm{Si}$ precipitates to the strength of direct metal laser sintered AlSi10Mg. Mater Sci Eng A 739:295-300. https:// doi.org/10.1016/j.msea.2018.10.055

80. Sato T, Hirosawa S, Hirose K, Maeguchi T (2003) Roles of microalloying elements on the cluster formation in the initial stage of phase decomposition of Al-based alloys. Metall Mater Trans A 34:2745-2755. https://doi.org/10.1007/s11661-003-0176-Z

81. Chen Y, Gao N, Sha G et al (2015) Strengthening of an Al-Cu-Mg alloy processed by high-pressure torsion due to clusters, defects 
and defect-cluster complexes. Mater Sci Eng A 627:10-20. https:// doi.org/10.1016/j.msea.2014.12.107

82. Chen Y, Gao N, Sha G et al (2016) Microstructural evolution, strengthening and thermal stability of an ultrafine-grained AlCu-Mg alloy. Acta Mater 109:202-212. https://doi.org/10.1016/ j.actamat.2016.02.050

83. Ungár T (2004) Microstructural parameters from X-ray diffraction peak broadening. Scr Mater 51:777-781. https://doi.org/10.1016/ j.scriptamat.2004.05.007

84. Williamson GK, Smallman RE (1956) III. Dislocation densities in some annealed and cold-worked metals from measurements on the X-ray Debye-Scherrer spectrum. Philos Mag 1:34-46. https://doi. org/10.1080/14786435608238074

85. Zhao YH, Liao XZ, Jin Z et al (2004) Microstructures and mechanical properties of ultrafine grained $7075 \mathrm{Al}$ alloy processed by ECAP and their evolutions during annealing. Acta Mater 52: 4589-4599. https://doi.org/10.1016/j.actamat.2004.06.017

86. Gorsse S, Hutchinson C, Gouné M, Banerjee R (2017) Additive manufacturing of metals: a brief review of the characteristic microstructures and properties of steels, Ti-6Al-4V and high-entropy alloys. Sci Technol Adv Mater 18:584-610. https://doi.org/10. 1080/14686996.2017.1361305

87. Song B, Dong S, Deng S et al (2014) Microstructure and tensile properties of iron parts fabricated by selective laser melting. Opt Laser Technol 56:451-460. https://doi.org/10.1016/j.optlastec. 2013.09.017

88. Zhang J, Gao N, Starink MJ (2010) Al-Mg-Cu based alloys and pure $\mathrm{Al}$ processed by high pressure torsion: the influence of alloying additions on strengthening. Mater Sci Eng A 527:34723479. https://doi.org/10.1016/j.msea.2010.02.016

89. Maamoun AH, Xue YF, Elbestawi MA, Veldhuis SC (2018) The effect of selective laser melting process parameters on the microstructure and mechanical properties of A16061 and AlSi10Mg alloys. Materials (Basel) 12. https://doi.org/10.3390/ma12010012

90. Zyguła K, Nosek B, Pasiowiec H, Szysiak N (2019) Mechanical properties and microstructure of AlSi10Mg alloy obtained by casting and SLM technique. World Sci News 104:462-472

91. Lewandowski JJ, Seifi M (2016) Metal additive manufacturing: a review of mechanical properties. Annu Rev Mater Res 46:151186. https://doi.org/10.1146/annurev-matsci-070115-032024

92. Carroll BE, Palmer T a, Beese AM (2015) Anisotropic tensile behavior of Ti-6Al-4V components fabricated with directed energy deposition additive manufacturing. Acta Mater 87:309-320. https://doi.org/10.1016/j.actamat.2014.12.054

93. Yadroitsev I, Thivillon L, Bertrand P, Smurov I (2007) Strategy of manufacturing components with designed internal structure by selective laser melting of metallic powder. Appl Surf Sci 254: 980-983. https://doi.org/10.1016/j.apsusc.2007.08.046

94. Chlebus E, Gruber K, Kuźnicka B et al (2015) Effect of heat treatment on the microstructure and mechanical properties of
Inconel 718 processed by selective laser melting. Mater Sci Eng A 639:647-655. https://doi.org/10.1016/j.msea.2015.05.035

95. Kawasaki M (2014) Different models of hardness evolution in ultrafine-grained materials processed by high-pressure torsion. J Mater Sci 49:18-34. https://doi.org/10.1007/s10853-013-7687-9

96. Tian YZ, Li JJ, Zhang P et al (2012) Microstructures, strengthening mechanisms and fracture behavior of $\mathrm{Cu}-\mathrm{Ag}$ alloys processed by high-pressure torsion. Acta Mater 60:269-281. https://doi.org/ 10.1016/j.actamat.2011.09.058

97. Bayramoglu S, Gür CH, Alexandrov IV, Abramova MM (2010) Characterization of ultra-fine grained steel samples produced by high pressure torsion via magnetic Barkhausen noise analysis. Mater Sci Eng A 527:927-933. https://doi.org/10.1016/j.msea. 2009.09.006

98. Vorhauer A, Pippan R (2004) On the homogeneity of deformation by high pressure torsion. Scr Mater 51:921-925. https://doi.org/ 10.1016/j.scriptamat.2004.04.025

99. Yan C, Hao L, Hussein A et al (2015) Microstructure and mechanical properties of aluminium alloy cellular lattice structures manufactured by direct metal laser sintering. Mater Sci Eng A 628:238-246. https://doi.org/10.1016/j.msea.2015.01.063

100. Prashanth KG, Scudino S, Klauss HJ et al (2014) Microstructure and mechanical properties of Al-12Si produced by selective laser melting: effect of heat treatment. Mater Sci Eng A 590:153-160. https://doi.org/10.1016/j.msea.2013.10.023

101. Harai Y, Ito Y, Horita Z (2008) High-pressure torsion using ring specimens. Scr Mater 58:469-472. https://doi.org/10.1016/j. scriptamat.2007.10.037

102. Xu C, Horita Z, Langdon TG (2008) The evolution of homogeneity in an aluminum alloy processed using high-pressure torsion. Acta Mater 56:5168-5176. https://doi.org/10.1016/j.actamat. 2008.06.036

103. Wongsa-Ngam J, Kawasaki M, Zhao Y, Langdon TG (2011) Microstructural evolution and mechanical properties of a $\mathrm{Cu}-\mathrm{Zr}$ alloy processed by high-pressure torsion. Mater Sci Eng A 528: 7715-7722. https://doi.org/10.1016/j.msea.2011.06.056

104. Zhilyaev AP, García-Infanta JM, Carreño F et al (2007) Particle and grain growth in an $\mathrm{Al}-\mathrm{Si}$ alloy during high-pressure torsion. Scr Mater 57:763-765. https://doi.org/10.1016/j.scriptamat.2007. 06.029

105. Edalati K, Miresmaeili R, Horita Z et al (2011) Significance of temperature increase in processing by high-pressure torsion. Mater Sci Eng A 528:7301-7305. https://doi.org/10.1016/j.msea.2011. 06.031

Publisher's note Springer Nature remains neutral with regard to jurisdictional claims in published maps and institutional affiliations. 